JAMP: Jurnal Adminitrasi dan Manajemen Pendidikan

Volume 3 Nomor 1 Maret 2020, Hal : 72-83

Tersedia Online di http://journal2.um.ac.id/index.php/jamp/

ISSN 2615-8574 (online)

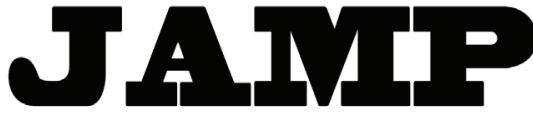

JURNAL ADMINISTRASI DAN MANAJEMEN PENDIDIKAN

\title{
KEPEMIMPINAN KEPALA SEKOLAH BERPRESTASI
}

\author{
Friska Fridiana Putri \\ Ibrahim Bafadal \\ Juharyanto \\ ffridiana@gmail.com \\ Universitas Negeri Malang, J1 Semarang 5 Malang 65145
}

\begin{abstract}
Principal's leadership is the main factor that supports schools in improving achievement. In this study aims to determine (1) Achievements that have been achieved by principals and schools that are led, (2) Characteristics of high school principals' leadership leadership, (3) Supporting factors for high school principals' leadership, and (4) inhibiting factors for school principals' leadership achievers in SD Negeri Tunjungsekar 1, Malang City. Where this is to find out the principal's leadership in improving achievement. The method used by researchers in this research is qualitative using a case study design. Data collection techniques used are in-depth interviews, participant observation, and study documentation. The subject of this study was the Principal of Malang Tunjungsekar 1 Elementary School, Malang, with the principal being the principal and teachers. Data analysis is done by reducing, presenting data, and drawing conclusions and verification. The results of this study are, (1) Principal achievers have a lot of achievements and the school they lead has a lot of achievements in various fields up to the national level. (2) Principal of SD Negeri Tunjungsekar 1 Malang has disciplined characteristics, has a lot of experience, is open, etc. (3) Good communication between the principal, teachers, students, guardians of students, and the community is able to be a supporter in improving achievement. (5) Barriers that occur in terms of time, energy, costs, and school conditions.
\end{abstract}

Keywords: Leadership, principal's leadership, achievement

Abstrak: Kepemimpinan kepala sekolah merupakan faktor utama yang mendukung sekolah dalam meningkatkan prestasi. Dalam penelitian ini memiliki tujuan untuk mengetahui (1) Prestasi yang telah diraih oleh kepala sekolah dan sekolah yang dipimpin, (2) Karakteristik kepemimpinan kepala sekolah berprestasi, (3) Faktor pendukung kepemimpinan kepala sekolah berprestasi, dan (4) Faktor penghambat kepemimpinan kepala sekolah berprestasi di SD Negeri Tunjungsekar 1 Kota Malang. Dimana hal tersebut untuk mengetahui kepemimpinan kepala sekolah dalam meningkatkan prestasi. Metode yang digunakan peneliti dalam penelitian ini yaitu kualitatif dengan menggunakan rancangan studi kasus. Teknik pengumpulan data yang digunakan yaitu wawancara mendalam, observasi partisipan, dan studi dokumentasi. Subjek penelitian ini adalah Kepala SD Negeri Tunjungsekar 1 Kota Malang, dengan sumber kepala sekolah dan guru. Analisa data dilakukan dengan cara reduksi, penyajian data, dan penarikan kesimpulan dan verifikasi. Hasil dari penelitian ini yaitu, (1) Kepala sekolah berprestasi memiliki prestasi yang banyak serta sekolah yang dipimpinnya memiliki prestasi yang banyak dalam berbagai bidang hingga level tingkat nasional. (2) Kepala SD Negeri Tunjungsekar 1 Kota Malang memiliki karakteristik yang disiplin, memiliki pengalaman berprestasi yang banyak, terbuka, dll. (3) Komunikasi yang baik antara kepala sekolah, guru, peserta didik, wali murid, dan masyarakat mampu menjadi pendukung dalam meningkatkan prestasi. (5) Hambatan yang terjadi dari segi waktu, tenaga, biaya, dan kondisi sekolah.

Kata Kunci: Kepemimpinan, kepemimpinan kepala sekolah prestasi 
Keberhasilan suatu lembaga pendidikan merupakan keberhasilan yang berasal dari seluruh faktor, faktor utama yakni berasal dari kepemimpinan kepala sekolah yang sesuai. Senada yang dikemukakan Mustiningsih (2013) bahwa, kepemimpinan merupakan suatu kegiatan untuk mempengaruhi, mengarahkan, membimbing, serta menggerakkan seluruh komponen sekolah agar senantiasa mencapai tujuan pendidikan yang diharapkan. Kepala sekolah memiliki hakikat yakni seseorang yang mendapatkan tugas dan kewajiban tambahan untuk memimpin suatu sekolah dan bertanggungjawab penuh dalam kegiatan lembaga pendidikan (Mulyasa, 2009). Kehadiran pemimpin pendidikan sangat penting perannya dalam suatu organisai, pemimpin senantiasa dijadikan sebagai panutan oleh bawahannya untuk melaksanakan tugas dan kewajibannya. Serorang pemimpin sangat berpengaruh dalam keberhasilan suatu sekolah. Keberhasilan suatu sekolah merupakan segala prestasi yang diraih oleh guru dan prestasi didik. Dengan prestasi yang telah diraih tersebut, guru dan peserta didik akan senantiasa termotivasi dengan melihat pemimpin yang memiliki prestasi banyak.

Prestasi yang diperoleh kepala sekolah dapat dijadikan sebagai bentuk motivasi bagi guru maupun peserta didik lainnya untuk semangat dalam meningkatkan prestasi sesuai dengan kemampuan tiap individu. Motivasi dan bimbingan yang didapat oleh kepala sekolah adalah faktor utama atas keberhasilan berbagai prestasi yang diraih oleh kepala sekolah. Menurut Calland dan Clark dalam Mulyasa (2009) mendefiniskan bahwa, motivasi adalah suatu tenaga pendorong atau penarik yang menyebabkan seseorang menjadi berubah dengan lebih baik dari sebelumnya. Sehingga dapat disimpulkan bahwa, dengan motivasi yang didapatkan oleh kepala sekolah menyebabkan kepala sekolah untuk giat dalam menunjukkan minat, mempunyai perhatian, dan antusias dalam mengikuti kegiatan dan kompetisi dengan sungguh-sungguh dan baik untuk mendapatkan prestasi dan pengalaman.

Kepala sekolah yang menyadari akan peran pemimpin berada pada hubungan dan interaksi yang berfokus antara pemimpin dan bawahan akan senantiasa memahami tujuan organisasi. Dengan pengetahuan dan pengalaman kepala sekolah dalam mendapatkan prestasi yang banyak dan berkualitas. Langkah-langkah yang dilakukan yakni berupa pengarahan, motivasi, serta memberikan kepemimpinan yang terbaik. Namun, jika guru dan peserta didik tidak diberikan pengarahan, motivasi, dan kepemimpinan yang terbaik maka prestasi guru dan peserta didik akan menurun karena tidak ada pendorong dalam mencapai prestasi yang diharapkan.

Prestasi yang telah diraih oleh kepala sekolah, guru serta peserta didik selain dari faktor pendorong pemimpin juga merupakan gambaran dari individu dalam berfikir positif dan maju dalam meningkatkan kreativitas, inovasi, ketrampilan, kemandirian, dan tanggung jawab individu sesuai dengan porsi masingmasing. Keberhasilan individu tersebut dapat dijadikan contoh bagi individu lain untuk meningkatkan prestasi yang dimiliki demi mewujudkan keberhasilan lembaga pendidikan yang lebih baik.

\section{METODE}

Penelitian dilakukan menggunakan pendekatan kualitatif. Jenis penelitian yang digunakan peneliti yaitu studi kasus, penelitian ini dilakukan di SD Negeri Tunjungsekar 1 Kota Malang. Menurut Sugiono (2012), dalam hal ini peneliti berperan sebagai instrumen yang hasilnya nanti lebih menekankan pada makna. Teknik pengumpulan data dalam penelitian ini yaitu wawancara mendalam, observasi partisipan, dan studi dokumentasi (Ulfatin, 2015).

Sumber data dari penelitian ini yaitu kepala sekolah dan guru, papan-papan visi misi tujuan sekolah, data prestasi kepala sekolah dan sekolah, penghargaan prestasi kepala sekolah dan sekolah. Peneliti menggunakan proses analisis data dari Miles dalam Ulfatin (2013) yang terdiri dari reduksi data, penyajian data, dan penarikan kesimpulan serta verifikasi. Penelitian menggunakan pengecekan keabsahan data untuk menguji tingkat kebenaran data yang diteliti, dengan cara triangulasi baik sumber maupun metode, pengecekan anggota, dan meningkatkan ketekunan. 


\section{HASIL}

\section{Prestasi Yang Telah Diraih Kepala Sekolah dan Sekolah Yang Dipimpin}

Sekolah yang dipimpin oleh kepala sekolah berprestasi memiliki prestasi yang banyak. Prestasi yang diraih oleh kepala sekolah meliputi dalam bidang guru berprestasi, supervisi, best practice. Pada level tingkat kecamatan, kota, provinsi, hingga nasional. Prestasi sekolah meliputi dalam bidang keolahragaan, guru berprestasi, pengelolaan kelas, green school festival, budaya mutu sekolah, karakter, kesenian, dan FLS2N. Pada level tingkat gugus, kecamatan, kota, provinsi, dan nasional.

Sekolah yang dipimpin oleh kepala sekolah berprestasi memiliki prestasi yang banyak karena kepala sekolah selalu berprinsip manajemen, turun tangan mempersiapkan kompetisi, memahami kompetisi, menerima kritik, dan mempersiapkan kompetisi dengan maksimal. Kepala sekolah senantiasa memberikan motivasi yang kuat kepada seluruh guru dan peserta didik agar senantiasa berprestasi. Kepala sekolah berprestasi senantiasa melakukan evaluasi secara menyeluruh dan berkelanjutan yang bertujuan untuk memperbaiki dalam keikutsertaan perwakilan sekolah pada kompetisi agar lebih baik lagi.

\section{Karakteristik Kepemimpinan Kepala Sekolah Berprestasi}

Karakteristik kepemimpinan kepala sekolah berprestasi sesuai dengan kompetensi kepala sekolah disertai strategi yang kuat agar berprestasi serta menjalankan kepemimpinannya dengan prinsip manajemen. Kepala sekolah berprestasi memiliki karakteristik yang disiplin serta selalu berbagi pengalaman berprestasi kepada seluruh warga sekolah. Dalam melakukan kepemimpinannya, kepala sekolah berprestasi sesuai dengan visi misi sekolah agar tidak terjadi kesalahan dalam melakukan kepemimpinannya. Kepala sekolah berprestasi memiliki gaya kepemimpinan demokratis, dimana kepala sekolah selalu memberikan kesempatan kepada guru dan peserta didik untuk menyampaikan ide terkait dalam meningkatkan prestasi sekolah. Kepala sekolah turut menjalin komunikasi yang baik dengan seluruh komponen sekolah untuk meningkatkan prestasi. Karakteristik kepala sekolah berprestasi senang dengan prestasi yang telah diraih oleh perwakilan sekolah, dengan kepala sekolah selalu memberikan penghargaan.

\section{Faktor Pendukung Kepemimpinan Kepala Sekolah Berprestasi}

Pendukung dalam kepemimpinan kepala sekolah berprestasi adalah kepala sekolah selalu mempertahankan prestasi dengan berkomunikasi baik dengan guru, peserta didik, wali murid dan masyarakat. Pendukung kepemimpinan kepala sekolah berprestasi berpacu dari banyaknya prestasi yang telah diraih, sehingga menyebabkan untuk senantiasa terdorong dalam meningkatkan prestasi.

\section{Faktor Penghambat Kepemimpinan Kepala Sekolah Berprestasi}

Hambatan dalam kepemimpinan kepala sekolah berprestasi karena dari segi waktu, tenaga, biaya, dan kondisi sekolah. Dari segi waktu dikarenakan pada hari sekolah kegiatan pembelajaran sudah full dan tidak ada waktu untuk melakukan persiapan kompetisi. Sedangkan hambatan dari segi biaya dan transportasi karena sekolah negeri sejatinya tidak bisa mengeluarkan dana sekolah secara terus menerus. Dengan hambatan tersebut kepala sekolah menyiapkan alternatif pemecahan yang terjadi tersebut. Hasil temuan secara keseluruhan dapat digambarkan dalam diagram aktif, seperti gambar di bawah ini. 


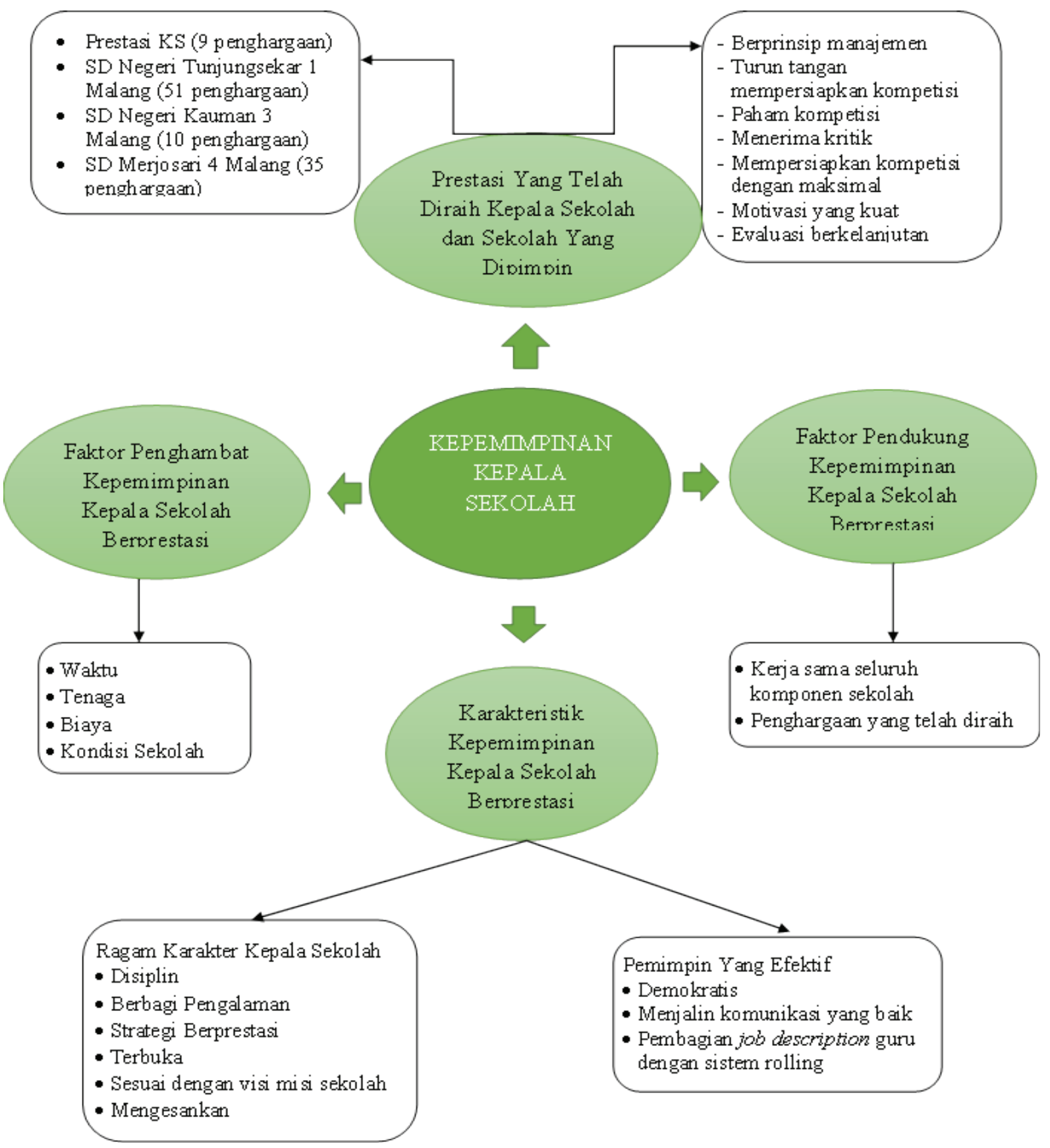

\section{PEMBAHASAN}

\section{Prestasi Yang Telah Diraih Kepala Sekolah dan Sekolah Yang Dipimpin}

Kepala sekolah membuktikan bahwa kepala sekolah mampu melaksanakan kepemimpinannya dengan mempengaruhi seluruh warga sekolah agar senantiasa berprestasi. Hal ini sesuai dengan teori yang dikemukakan oleh Susanto (2016) bahwa, kepemimpinan kepala sekolah adalah suatu bagian penting untuk melakukan kegiatan pengelolaan sekolah. Pengelolaan sekolah yang dipimpin oleh kepala sekolah akan terbukti sesuai dengan hasil belajar peserta didik dan prestasi yang diperoleh sekolah. Bafadal (2016:3) menjelaskan bahwa, kepemimpinan kepala sekolah sering di definisikan sebagai kunci utama dari sebuah sekolah yang baik, sekolah yang efektif, sekolah yang berkualitas, dan sekolah yang bertaraf internasional dipandang baik oleh seluruh masyarakat.

Hasil penelitian dapat disimpulkan bahwa kepemimpinan kepala sekolah mampu meningkatkan 
prestasi karena faktor dari kepala sekolah yakni, berprinsip manajemen, turun tangan dalam mempersiapkan kompetisi, memahami kompetisi, menerima kritik, mempersiapkan kompetisi dengan maksimal, memberikan motivasi yang kuat, dan senantiasa melakukan evaluasi secara berkelanjutan.

Dapat disimpulkan bahwa kepemimpinan kepala sekolah mmapu mempengaruhi seluruh warga sekolah untuk mengikuti suatu kompetisi perlombaan dengan maksimal, terbukti dengan prestasi sekolah yang diraih sangat banyak

\section{Karakteristik Kepemimpinan Kepala Sekolah Berprestasi}

Keberhasilan sekolah dalam mendapatkan prestasi tergantung dari kepemimpinan kepala sekolah. Kepala sekolah memiliki berbagai macam karakter yang mampu menghasilkan sekolah yang dipimpin menjadi berprestasi. Karakter kepemimpinan kepala sekolah dapat dilihat dari cara kepala sekolah dalam memimpin warga sekolah dan kehadiran kepala sekolah sebagai pemimpin yang dinilai baik oleh warga sekolah semua. Karakteristik kepemimpinan kepala sekolah dalam meningkatkan prestasi ditunjukkan dalam wujud, ragam karakter kepala sekolah, pemimpin yang efektif, keberhasilan. Dalam meningkatkan prestasi kepala sekolah harus menjalin komunikasi yang baik dengan seluruh warga sekolah, sesuai dengan teori Ambarita (2015) bahwa, kepala sekolah yang berhasil dan efektif akan senantiasa berkomunikasi dengan semua pihak dengan efektif.

Hasil penelitian dapat disimpulkan bahwa karakteristik kepemimpinan kepala sekolah yakni, disiplin, senantiasa berbagi pengalaman, memiliki strategi berprestasi, terbuka, memimpin sesuai dengan visi misi sekolah, mengesankan, demokratis, menjalin komunikasi yang baik, dan pembagian job description guru dengan menggunakan sistem rolling.

Karakteristik kepala sekolah dalam melakukan kepemimpinannya sangat disambut baik oleh guru, peserta didik, wali murid, dan masyarakat karena mampu meningkatkan prestasi yang diraih oleh sekolah.

\section{Faktor Pendukung Kepemimpinan Kepala Sekolah Berprestasi}

Pendukung dalam kepemimpinan kepala sekolah untuk meningkatkan prestasi dikarenakan adanya dukungan dan kerja sama yang kuat antara seluruh warga sekolah yakni, guru, peserta didik, wali murid, dan masyarakat yang senantiasa memberikan dorongan dan semangat dalam meningkatkan prestasi. Wahjosumidjo (2007) menyatakan bahwa, kemampuan yang harus diwujudkan kepala sekolah sebagai leader dapat dilihat dari segi kepribadian, pengetahuan terhadap pendidik dan tenaga kependidikan, visi dan misi sekolah, kemampuan mengambil keputusan dan kemampuan dalam berkomunikasi dengan seluruh warga sekolah. Penghargaan prestasi yang telah diraih sebelumnya oleh sekolah juga mampu menajadikan suatu dukungan yang kuat agar berpacu untuk selalu berprestasi kedepannya. Jadi, dengan adanya dukungan tersebut dapat mendorong kepala sekolah untuk senantiasa melaksanakan kepemimpinannya dengan maksimal untuk menghasilkan prestasi yang diharapkan.

\section{Faktor Penghambat Kepemimpinan Kepala Sekolah Berprestasi}

Penghambat dalam kepemimpinan kepala sekolah untuk meningkatkan prestasi yakni karena dari segi waktu, tenaga, biaya, dan kondisi sekolah. Adanya hambatan tersebut akan meminimalisir prestasi yang ingin dicapai oleh sekolah. Dengan hambatan yang terjadi kepala sekolah memiliki beberapa strategi alternatif untuk mengatasi hambatan yang terjadi. Hal tersebut sesuai dengan teori yang dikemukakan Mulyasa (2013) bahwa, kepala sekolah harus mempunyai cara dan strategi yang tepat untuk memberdayakan seluruh warga sekolah dengan cara kerjasama, memberikan kesempatan memberikan ide dan kepala sekolah juga wajib mendorong seluruh warga sekolah agar senantiasa terlibat pada seluruh program dan kegiatan sekolah. 


\section{KESIMPULAN}

Sekolah yang dipimpin oleh kepala sekolah berprestasi memiliki prestasi yang banyak dalam berbagai bidang dan tingkat level prestasi. Sekolah yang dipimpin oleh kepala sekolah berprestasi memiliki prestasi yang banyak karena kepala sekolah selalu berprinsip manajemen, turun tangan mempersiapkan kompetisi, memahami kompetisi, menerima kritik, dan mempersiapkan kompetisi dengan maksimal. Kepala sekolah senantiasa memberikan motivasi dan senantiasa melakukan evaluasi secara menyeluruh dan berkelanjutan. Karakteristik kepemimpinan kepala sekolah berprestasi ditunjukkan dengan disiplin, senantiasa berbagi pengalaman, memiliki strategi berprestasi, terbuka, memimpin sesuai dengan visi misi sekolah, mengesankan, demokratis, menjalin komunikasi yang baik, dan pembagian job description guru dengan menggunakan sistem rolling. Kerja sama yang baik seluruh warga sekolah dan penghargaan yang telah diraih sebelumnya mampu menjadikan pendukung dalam kepemimpinan kepala sekolah. Hambatan yang terjadi dalam kepemimpinan kepala sekolah untuk mendapatkan prestasi disebabkan dari segi waktu, biaya, tenaga dan kondisi sekolah.

\section{DAFTAR RUJUKAN}

Ambarita, A. 2015. Kepemimpinan Kepala Sekolah. Yogyakarta: Graha Ilmu.

Bafadal, I. 2016. Penilaian Kinerja Kepala Sekolah Sebagai Pemimpin Pembelajaran Dalam Rangka Peningkatan Akuntabilitas Sekolah. Manajemen Pendidikan, 25(1), 1-9. Dari http://ap.fip.um.ac.id/wp-content/ uploads/2015/05/02-Ibrahim-Bafadal.pdf.

Mulyasa, E. 2009. Menjadi Kepala Sekolah Profesional. Bandung: Remaja Rosdakarya.

Mulyasa, E. 2013. Menjadi Kepala Sekolah Profesional. Bandung: Remaja Rosdakarya.

Mustiningsih. 2013. Pengantar Kepemimpinan Pendidikan. Malang: Fakultas Ilmu Pendidikan Universitas Negeri Malang.

Sugiyono. 2012. Memahami Penelitian Kualitatif. Jakarta: Bumi Aksara.

Susanto. 2016. Ketahanmalangan Kepemimpinan Kepala Sekolah: Salah Satu Faktor Penentu Keberhasilan Kepala Sekolah. Yogyakarta: Deepublish.

Ulfatin, Nurul. 2013. Metode Penelitian Kualitatif di Bidang Pendidikan. Malang: Fakultas Ilmu Pendidikan Universitas Negeri Malang.

Ulfatin, Nurul. 2015. Metode Penelitian Kualitatif di Bidang Pendidikan: Teori dan Aplikasinya. Malang: Media Nusa Creative.

Wahjosumidjo. 2007. Kepemimpinan Kepala Sekolah: Tinjauan Teoritik dan Permasalahannya. Jakarta: Raja Grafindo Persada. 